\title{
ANALISIS SIFAT FISIKA ULTISOL TIGA TAHUN SETELAH PEMBERIAN BAHAN ORGANIK SEGAR DI DAERAH TROPIS BASAH SUMBAR
}

\author{
Yulnafatmawita*), Rice Agmi Naldo, dan Azwar Rasyidin \\ F akultas Pertanian U niversitas Andalas Padang \\ *)Corresponding author:ita_lamsoeddin@yahoo.com
}

\begin{abstract}
Ultisols as a marginal land need to be reclaimed especially the soil aggregate stability (SAS) under wet tropical area. A research about application of 3 types of fresh organic matter (FOM): Gliricidia sepium dan Tithonia diversifolia) aiming to improve SAS was conducted in Ultisol Limau Manis, wet tropical area, West Sumatra. Fresh organic matter was added to soil at 3 different slope $(3,12$, dan $25 \%$ slope $)$ in early 2008 , then the soil was planted by corn for 4 times until the end of 2009. Corn biomass was return to the land as mulch between crop rows every harversting. The land, then, was fallowed for 1 year (in 2010) before the soil was sampled in 2011 for the physical properties analyses. The results showed that soil organic matter (SOM) content, SAS, permeabilitas, and total pore at $0-20 \mathrm{~cm}$ soil depth from plots applied with FOM at all classes of slope were still higher than those control plots. From 3 FOM added, plot added with Tithonia diversifolia still showed better soil physical properties ( $\mathrm{SOM}=$ $8.3 \%$, SAS $=83$ ). It means that FOM application on Ultisol under wet tropical raiforest still gave effect until 3 years after application.
\end{abstract}

Key Words: U Itisol, stabilitas aggregat, bahan organik segar, bahan organik tanah

\section{PENDAHULUAN}

Permasalahan utama pada Ultisol disamping kondisi perharaannya yang tergolong miskin juga sifat fisiknya yang kurang menguntungkan. Salah satu sifat fisiknya yang menonjol yaitu tekstur tanah yang dicirikan oleh kandungan liat yang tinggi dan debu rendah. Kondisi tekstur ini mendasari banyaknya masalah lain pada Ultisol, diantaranya masalah retensi dan transmissi air, pemadatan tanah, dan penetrasi akar. Distribusi pori yang kurang seimbang, karena didominasi oleh pori mikro, menyebabkan aerasi kurang baik, laju infiltrasi rendah, dan peka erosi. Selanjutnya, kemantapan aggregat dan permeabilitas tanah juga rendah karena kandungan bahan organik yang rendah (Sarief,1989).

Bahan organik (BO) sebagai salah satu bahan pembentuk tanah berperan dalam memperbaiki, mempertahankan, ataupun meningkatkan sifat-sifat, baik sifat fisika, kimia, maupun biologi tanah mineral. Hal ini disebabkan karena BO setelah mengalami pelapukan akan membentuk senyawa antara yang agak stabil dan bersifat koloid, yang sangat reaktif. Sifat koloid inilah yang membuat BO mampu memperbaiki sifat fisika dan kimia tanah. Diantaranya yang utama terhadap sifat fisik tanah adalah membentuk dan memantapkan aggregat tanah. Tanah dengan aggregat yang mantap akan mampu mempertahankan kondisi tanah dari serangan energi luar seperti energi kinetik curah hujan, energi pengolahan tanah, dan sebagainya. Dengan demikian, laju infiltrasi tanah akan bisa dipertahankan, sehingga aliran permukaan bisa diantisipasi dan kemungkinan erosi bisa terhindar.

Akan tetapi, kandungan $\mathrm{BO}$ tanah di daerah tropis basah cendrung rendah, walaupun produksi biomasa tanaman melimpah. Seperti yang dilaporkan oleh Yulnafatmawita et al.(2008) bahwa Ultisol Limau Manis mempunyai kandungan BO yang rendah $(2.9 \%)$ pada top soil. Kondisi iklim dengan suhu dan curah hujan yang tinggi seperti di daerah Limau Manis Padang, Sumbar telah menyebabkan laju pelapukan BO cepat. Apalagi pada lahan pertanian tanaman semusim yang pada umumnya 
tanahnya diolah intensif. Yulnafatmawita (2006) melaporkan bahwa kandungan BO Ultisol Limau menjadi lahan pertanian dengan tanaman tua dan tanaman semusim telah menurunkan status $\mathrm{BO}$ tanah sekitar $42 \%$ (dari $9.86 \%$ menjadi $5.75 \%$ ) dan $55 \%$ (dari $9.86 \%$ menjadi $4.42 \%$ ) pada lapisan 0 $10 \mathrm{~cm}$ dan sekitar $45 \%$ (dari $3.79 \%$ menjadi $2.09 \%$ ) and $18 \%$ (from $3.79 \%$ menjadi $3.10 \%$ ) pada lapisan $10-20 \mathrm{~cm}$.

Pengolahan tanah yang intensif telah menyebabkan peningkatan oksidasi BO dalam tanah serta pelepasan gas $\mathrm{CO} 2 \mathrm{ke}$ udara. Penipisan kandungan BO tanah dengan waktu akan memicu terjadinya bencana alam. Oleh sebab itu, salah satu usaha untuk mengantisipasi terjadinya bencana alam, kandungan BO tanah haruslah dipertahankan pada level tertentu. Bahan organik mampu memperbaiki sifat fisika tanah, seperti memodifikasi pengaruh tekstur yang berliat tinggi pada Ultisol.

Aggregat tanah yang terbentuk dengan agen pengikat BO akan lebih stabil, terutama bila terjadi pembasahan secara tiba-tiba. Hal ini sangat dibutuhkan bagi tanah-tanah di daerah super basah Sumatera Barat, seperti Ultisol. Ultisol merupakan tanah yang mempunyai sifat fisika yang kurang menguntungkan, diantaranya kandungan BO dan stabilitas aggregat tanah yang rendah, serta permeabilitas yang lambat. Yulnafatmawita (2006) melaporkan bahwa ada korelasi positif antara kandungan BO dan stabilitas aggregat (SA) tanah Ultisol Limau Manis. Oleh sebab itu, penambahan BO untuk perbaikan aggregat Ultisol Limau Manis merupakan tindakan yang tepat.

Berbagai jenis sumber BO bisa ditambahkan ke dalam tanah. Pemilihan salah satu BO yang diplikasikan sangat tergantung pada keberadaan atau ketersediaan dari BO tersebut, apakah dalam bentuk pupuk kandang, kompos, sisa tanaman, ataupun bahan segar tanaman yang masih hijau. Diantara sumber tersebut BO segar kelihatannya akan lebih efisien karena bisa lansung diproduksi pada lahan pertanian. Namun, belum diketahui secara pasti berapa lama BO segar yang ditambahkan bisa dipertahankan dalam tanah. Hal ini penting bagi interval waktu pemberian $\mathrm{BO}$ ke dalam tanah. Oleh sebab itu, perlu dicek berapa lama lahan yang diberi BO segar tersebut bisa dipertahankan sifatnya.

\section{METODOLOGI}

Penelitian ini merupakan percobaan lanjutan dari suatu percobaan pemberian BO dalam bentuk bahan hijauan tanaman ke dalam tanah pada tahun 2008 di lapangan. Lokasi percobaan berada di daerah Limau Manis kecamatan Pauh, kaki gunung Gadut Kodya Padang $\left(100^{\circ} 27^{\prime} 46.5^{\prime \prime}\right.$ E, $00^{\circ}$ 54'28.2" S, $\pm 276 \mathrm{~m} \mathrm{dpl.).} \mathrm{Daerah} \mathrm{ini}$ menerima curah hujan $>5000 \mathrm{~mm}$ pertahun (Rasyidin, 1994), tanahnya didominasi oleh Ultisol (Imbang et al, 1994) dengan sub group Udults. Tanah ini mempunyai rejim kelembaban tanah udik, drainase baik, dan mempunyai epipedon okrik diatas horizon argilik (Fiantis, 2007), tekstur liat dan topografinya berombak sampai berbukit (Yulnafatmawita et al, 2010a).

Bahan organik segar hanya diapplikasikan satu kali ke lahan dengan dosis 20 t/ha pada tahun 2008. Bahan organik yang digunakan berasal dari 2 spesies tanaman, yaitu Gliricidia sepium, and Tithonia diversifolia. Bahan organik dipotong-potong, dicampurkan ke tanah sampai kedalaman $20 \mathrm{~cm}$, lalu dibiarkan (diinkubasi) selama satu (1) bulan sebelum jaguung ditugal pada tahun 2008 dan 2009. Applikasi BO ini dilakukan pada lahan dengan 3 lereng yang berbeda $(3 \%, 12 \%$, dan 25\%). Biomasa tanaman setiap setelah panen (2008 dan 2009) diletakkan kembali diatas plot percobaan diantara baris tanaman. Pada tahun 2010 plot diberakan, lalu tanah kembali di sampel pada awal 2011.

Sampel tanah, utuh, terganggu, serta beraggregat utuh, diambil pada lapisan 0-20 $\mathrm{cm}$ untuk analisis BV dan TRP (metoda Gravimetri), Permeabilitas (berdasarkan Hk.Darcy), BO (metoda Walkley \& Black) dan SA tanah (metoda ayakan kering dan basah), persen aggregasi (metoda ayakan kering) dan indeks plastisitas tanah di laboratorium Ilmu Tanah Fak. Pertanian Univ. Andalas Padang. Selanjutnya, data yang diperoleh dianalisis sidik ragamnya, dan dilanjutkan dengan uji lanjut HSD (5\%) dengan Statistix 8.0, jika F-hitung > F-tabel. 
Di samping itu, data yang diperoleh juga dibandingkan dengan kriteria sifat fisik tanah (LPT, 2006).

\section{HASIL DAN PEMBAHASAN}

Sifat Fisika Tanah Setelah 3 Tahun Pemberian BO Segar

Sifat fisika Ultisol di daerah Limau Manis Kodya Padang setelah diberi BO segar pada tahun 2008, lalu ditanami jagung untuk sampai tahun 2009, lalu diberakan setahun (tahun 2010) sebelum diambil sampel tanahnya diawal tahun 2011dapat dilihat pada Tabel 1. Selanjutnya data masing-masing parameter disajikan dalam bentuk grafik.

Dari Grafik 1 terlihat bahwa kandungan BO tanah dari plot yang diberi BO segar tiga tahun sebelumnya masih memperlihatkan kandungan yang cukup tinggi dibandingkan dengan plot yang ti dak diberi BO (kontrol). Hal ini mungkin disebabkan dari efek penambahan BO terhadap kesuburan fisik maupun kimia tanah, sehingga tanaman tumbuh lebih subur dan produksi bahan hijauannya yang bisa dikembalikan ke dalam tanah juga lebih besar. Berdasarkan hasil penelitian Yulnafatmawita, et al. (2010) diperoleh bahwa biomasa jagung dari plot yang diberi BO segar jauh lebih banyak dibanding plot kontrol.

Diantara dua macam BO segar (Gliricidia dan Tithonia) yang diapplikasikan, walaupun tidak berbeda nyata diantaranya, plot yang diberi tithonia masih memperlihatkan kecendrungan mempunyai kandungan $\mathrm{BO}$ tanah yang lebih tinggi pada semua lereng. Hal ini kelihatannya berkaitan erat dengan sifat tithonia yang cepat melapuk dan menyumbangkan koloidnya sebagai perbaikan fisika tanah maupun haranya bagi sumber hara tanaman. Tanaman yang tumbuh cepat akibat tersedianya hara yang banyak dan lingkungan perakaran yang kondusif telah memberikan biomasa yang cepat juga untuk dikembalikan ke dalam tanah.
Peningkatan BO tanah juga berpengaruh pada laju permeabilitas tanah, indeks stabilitas aggregat tanah, nilai bobot isi tanah, dan total ruang pori tanah. Nilai laju permeabilitas tanah masih memperlihatkan perbedaan antara plot yang diberi dan yang tidak diberi BO segar, walaupun pada lahan dengan slope 3\% tidak berbeda nyata. Laju permeabilitas tanah ini sebanding dengan kandungan $\mathrm{BO}$ tanah. Hal ini disebabkan karena $\mathrm{BO}$ adalah salah satu agen pengikat butir dan pemantap aggregat tanah. Khusus tanah berliat tinggi seperti Ultisol Limau Manis ini, BO sangat berperan dalam menyeimbangkan pori tanah antara pori mikro (biasanya dominan) dengan pori makro yang akan melewatkan air.

Bahan organik, selanjutnya, juga mempengaruhi nilai bobot isi (BV) tanah. Bahan organik berbanding terbalik dengan nilai $\mathrm{BV}$, karena di samping masanya rendah persatuan volume BO juga meningkatkan pori tanah atau menurunkan masa tanah persatuan volumenya. Nilai BV tanah pada plot yang diapplikasikan BO segar berbeda nyata dibanding kontrol.

Penurunan BV tanah akan berdampak pada peningkatan total ruang pori tanah. Walaupun berbeda tidak nyata, nilai TRP tanah dari plot yang diberi BO segar cendrung lebih tinggi dari plot kontrol. Hal ini sesuai dengan yang didapatkan oleh Yulnafatmawita et al. (2006, 2008, 2010) bahwa peningkatan $\mathrm{BO}$ tanah menurunkan nilai BV tanah dan meningkatkan persentase total ruang pori tanah.

Kandungan BO tanah berbanding lurus dengan indeks stabilitas aggregat tanah. Seperti halnya kandungan BO tanah, indeks stabilitas aggregat tanah dari plot yang diberi BO segar cendrung lebih tinggi dibanding plot kontrol, walaupun berbeda tidak nyata menurut statistik. Hal ini disebabkan karna BO berperan dalam pemantapan aggregat tanah, namun kemantapan aggregatnya sudah mulai menurun. Koloid organik yang dihasilkan dari dekomposisi BO tersebut beserta exresi akar dan mikroba perombak bersama-sama 

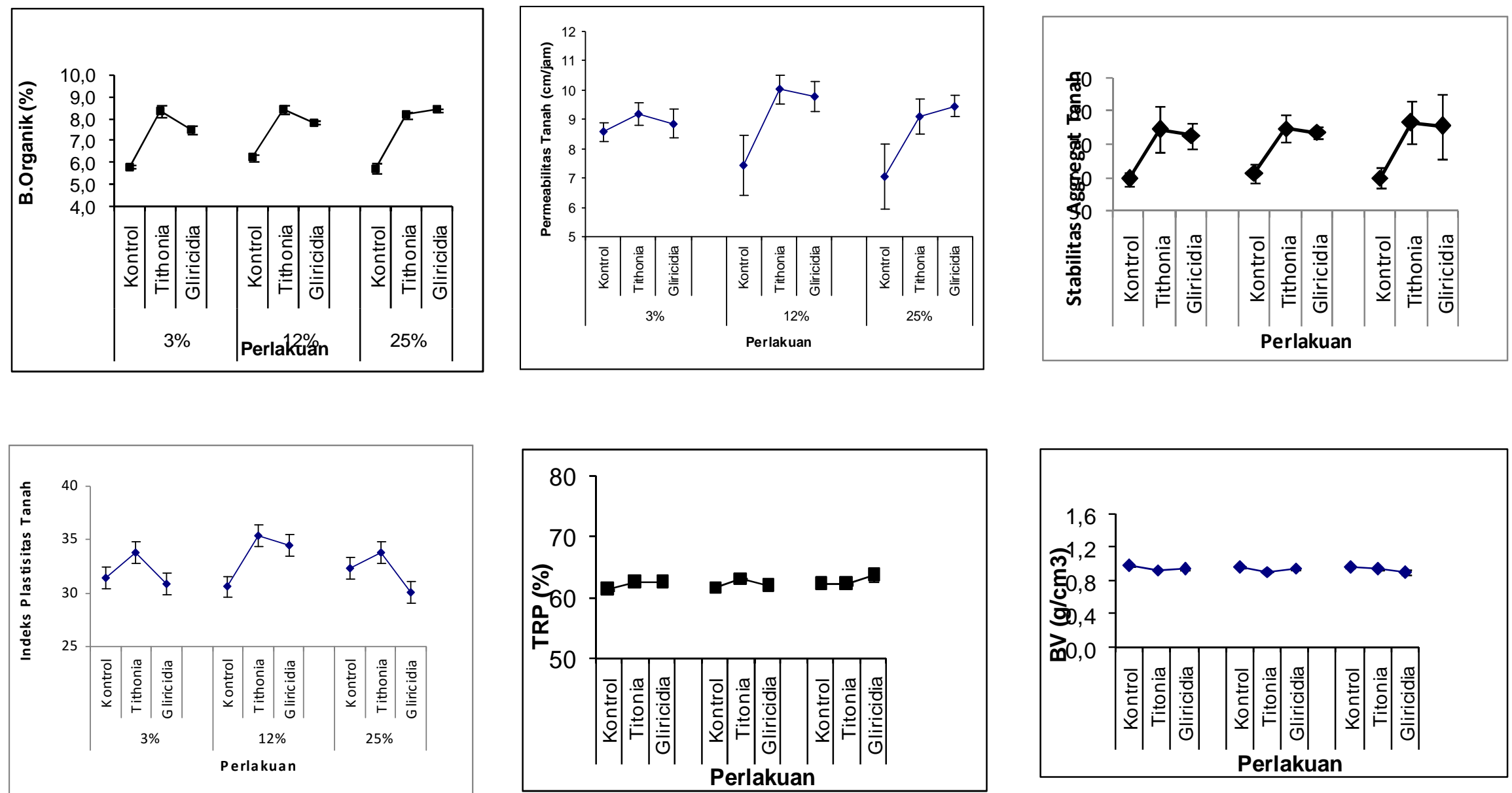

Gambar 1. Beberapa sifat fisika Ultisol Limau Manis setelah tiga tahun pemberian BO segar 
membantu memantapkan aggregat tanah dan tahan terhadap pembasahan tiba-tiba. Seperti yang disampaikan oleh Sarief(1989) bahwa aggregat tanah yang dibentuk oleh agen BO akan lebih stabil terhadap air, karena $\mathrm{BO}$ bersifat hidrofobik.

Perbandingan Sifat Fisika Tanah dengan Sifat Fisika Awal, Tahun 2008, dan 2009

Dari beberapa sifat fisika tanah yang dianalisis, BO tanah pada semua plot disetiap slope cendrung lebih tinggi dari tahun-tahun sebelumnya. Peningkatan ini mungkin terjadi karena lahan diberakan atau tidak diolah selama satu tahun, sehingga BO yang dihasilkan akan tetap terakumulasi pada tanah tersebut. $\mathrm{P}$ engolahan tanah menyebabkan BO tanah akan terekpos ke atmosfir dan mudah dijangkau mikroba perombak, sehingga oksidasi BO secara enzimatik akan dipercepat. Seperti yang disampaikan oleh Yulnafatmawita et al (2003) bahwa dengan semakin intensifnya pengolahan tanah, maka semakin tinggi $\mathrm{CO} 2$ yang diemisikan ke udara sebagai akibat dari oksidasi BO.

Seperti halnya BO tanah, maka indeks stabilitas aggregat tanah pada tahun 2011 masih beada pada kondisi tertinggi seperti pada tahun 2008, atau meningkat lagi setelah sempat menurunn pada tahun 2009. Hal ini disebabkan oleh peningkatan $\mathrm{BO}$ tanah yang memantapkan dan menstabilkan aggregat tanah selama satu (1) tahun tanpa terganggu oleh pengolahan tanah.

Akan tetapi, nilai bobot isi tanah tidak memperlihatkan perubahan dari data pada tahun 2009, namun cendrung meningkat dari pada tahun 2008, tahun pertama pengolahan tanah dan tahun pemberian BO segar (perlakuan). Walaupun demikian, berdasarkan kriteria sifat fisika tanah yang dikemukan oleh LPT (2006), bobot isi (BV) tanah ini mulai dari awal sebelum penambahan BO segar dan pengolahan tanah sampai tahun 2011 masih berada pada kriteria yang sama, yaitu sedang.
Peningkatan nilai BV tanah berdampak pada penurunan nilai total ruang pori tanah, karena nilai $\mathrm{BV}$ berbanding terbalik $d$ engan persen total runag pori tanah. Akan tetapi, berdasarkan kriteria sifat fisika tanah yang dikemukan oleh LPT (2006), nilai total ruang pori (TRP) tanah tanah ini mulai dari awal sebelum penambahan BO segar dan pengolahan tanah sampai tahun 2011 masih berada pada kriteria yang sama, yaitu sedang.

Belum berubahnya kriteria nilai BV dan TRP tanah dari tanah sebelum diolah disebabkan kemungkinan oleh tekstur Ultisol Limau Manis yang didominasi oleh partikel halus, terutama liat $(>60 \%)$. Tanah bertekstur liat mempunyai total ruang pori yang tinggi, walaupun dominan pori kecil namun total volume yang diisi udara telah menyebabkan bobot tanah persatuan volumenya lebih rendah dibanding tanah bertekstur pasir.

Dari pengukuran permeabilitas yang dilakukan di laboratorium, terlihat bahwa nilai laju permeabilitas tanah semenjak awal sangat bervariasi. Pada tahun 2011 ini menunjukan nilai laju permeabilitas tanah yang sudah mulai stabil tidak bervariasi banyak seperti pada tahun 2008 saat pertama pengolahan tanah dilakukan. Kelihatannya, pengaruh pengolahan tanah lebih dominan dibanding pengaruh penambahan BO terhadap variasi nilai laju permeabilitas tanah ini.

Pengolahan tanah telah menggemburkan tanah dan poros. Tingkat keporosan tanah juga meningkat dengan keberadaan BO segar yang ditambahkan, yang pada tahun 2008 belum sempurna melapuk. Setelah tiga tahun dari saat penambahan BO dan setelah selama satu tahun pemberaan menyebabkan nilai laju permeabilitas tanah kan kriteria yang dikeluarkan oleh LPT (2006) bahwa laju permeabilitas tanah naik dari lambat (awal sebelum pengolahan dan penambahan BO segar) menjadi agak cepat pada tahun 2011. 


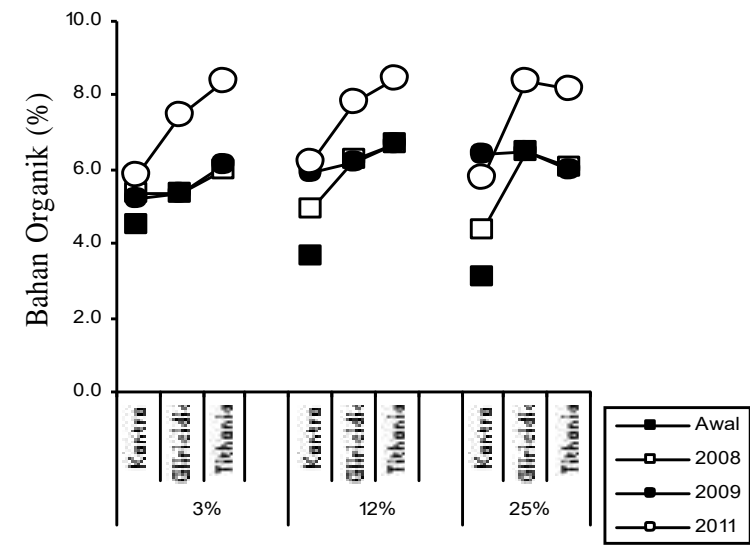

Jenis BO Segar dan Slope

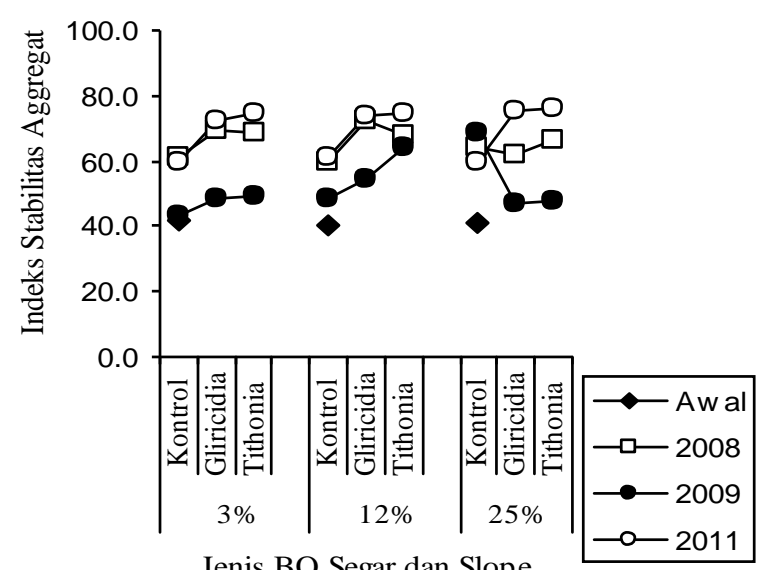

Jenis BO Segar dan Slope

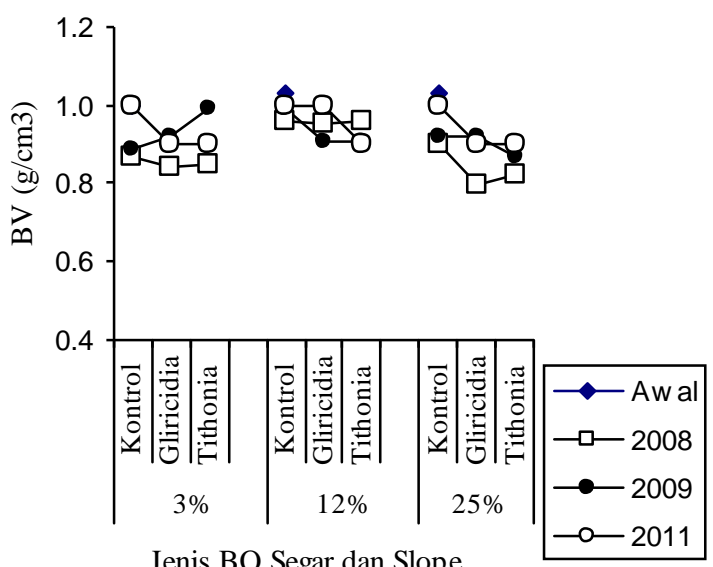

Jenis BO Segar dan Slope

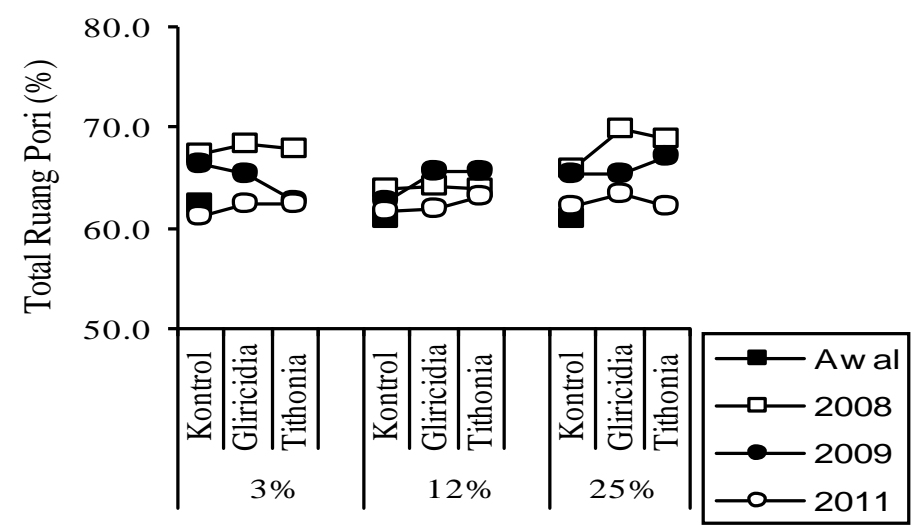

Jenis BO Segar dan Slope

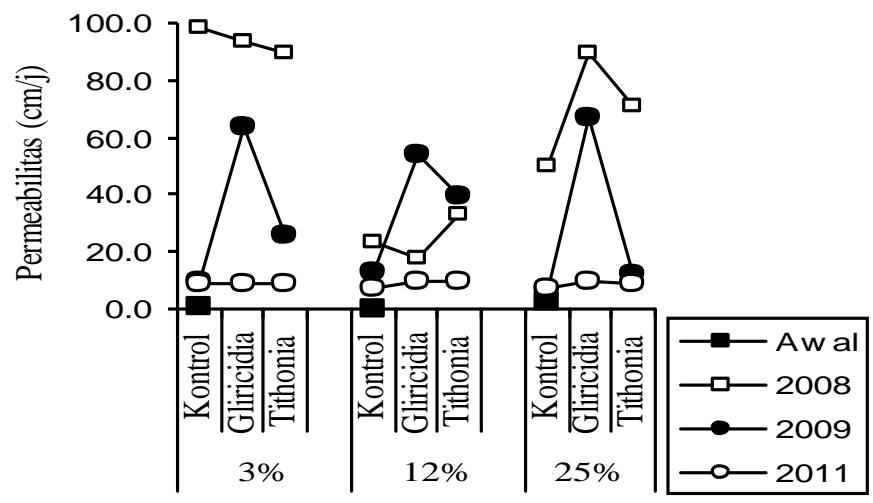

Jenis BO Segar dan Slope

Gambar 2. Perbandingan sifat fisika tanah Ultisol Limau Manis sejak awal sampai tiga tahun setelah pemberian BO segar 


\section{KESIMPULAN}

Berdasarkan hasil penelilitian dapat disimpulkan bahwa tiga tahun setelah pemberian BO segar pada Ultisol di bawah kondisi $\mathrm{CH}$ yang tinggi masih dapat mempengaruhi sifat fisik tanah dibanding yang tidak diberi BO, diantaranya:

1. Kandungan $\mathrm{BO}$ dan permeabilitas tanah dari bekas plot di $\mathrm{BO}$ segar lebih tinggi dan $\mathrm{BV}$ tanah lebih rendah dari kontrol. Dibanding tanah awal, 2008 dan 2009, kandungan BO tanah pada pada tahun 2011 lebih tinggi, BV hampir sama, sedangkan laju permeabilitas tanah cendrung stabil, lebih rendah dari tahun 2008-2009, namun meningkat dari lambat (tanah awal sebelum pengolahan) menjadi agak cepat

2. Indeks stabilitas aggregat tanah masih memperlihatkan kecendrungan peningkatan pada plot bekas diberi BO segar dibanding kontrol. Nilainya masih lebih tinggi dibanding tanah awal, tahun 2008 dan 2009

3. BO segar dari jenis Tithonia diversifolia cendrung lebih baik dibanding Gliricidia dalam memperbaiki sifat fisika tanah, terutama kandungan $\mathrm{BO}(8.3 \%)$, permeabilitas $(10.02 \mathrm{~cm} / \mathrm{j})$, dan indeks stabilitas aggregat tanah (83).

\section{DAFTAR PUSTAKA}

Baver, L.D. 1972. Soil Physics. Fourth Edition. John Wiley \& Sons Inc. New York, $498 \mathrm{p}$

Fiantis, D. 2007. Morfologi dan Klassifikasi Tanah. Jurusan Tanah. Fakultas Pertanian Universitas Andalas Padang. 193 hal

Imbang, I. N. D. R., Rasyidin. A., Adrinal. Maira, L., dan Hermansah, 1994. Klasifikasi tanah kebun percobaaan Fakultas Pertanian Universitas Andalas di Limau Manis Kodya Padang. Laporan Pernelitian OPF. Lembaga Penelitian Universita Andalas. 50 hal.
Lembaga Penelitian Tanah. 2006. Metoda analisis sifat fisika tanah. LPT Bogor.

Rasyidin, A 1994. The method for measuring rates of weathering and rates of soil formation in watershed. Dissertation. Tottory Univ. Japan, $110 \mathrm{p}$.

Sarief, S. 1989. Fisika-kimia tanah pertanian. Pustaka Buana Bandung.

Yulnafatmawita, So, H.B., Dalal, R.C., and Menzies, N.W. 2003. $\mathrm{CO}_{2}$ emission from different aggregate size fractions following physical disruption: Implication for tillage practices. Proceedings The $16^{\text {th }}$ Triennial ISTRO Conference, 13-18 July 2003, Brisbane, Queensland, Australia. p1396-1402

Yulnafatmawita. 2006. Hubungan antara status C-organik dan stabilitas aggregat tanah Ultisol Limau Manis Padang akibat perubahan penggunaan lahan. Proceeding Seminar BKS-PTN, 25-28 April 2006 Jambi.

Yulnafatmawita, Adrinal, dan Daulay, A.F. 2008. Pengaruh pemberian beberapa jenis bahan organik terhadap stabilitas aggregat tanah Ultisol Limau Manis. Solum J. Vol. V(1):7-13

Yulnafatmawita, Saidi, A., Gusnidar, Adrinal, dan Suyoko. 2010a. Peranan bahan hijauan tanaman dalam peningkatan bahan organik dan stabilitas aggregat tanah Ultisol Limau Manis yang ditanami jagung (Zea mays L.). J. Solum Vol VII(1):37-48

Yulnafatmawita, Gusnidar, and Amrizal Saidi. 2010b. Role of organic matter in situ for agregate stability improvement of Ultisol in West Sumatra and chilli (Capsicum annum) production. Proceeding Intern. Seminar on Food and Agric. Sciences (ISFAS) 17-18 Feb 2010, Bukittinggi. 